Vol. ( 3 ), No. ( 9 ), Oct. 2015, PP. 463 - 497

\title{
THE ATTITUDES OF GENERAL EDUCATION PRE-SERVICE TEACHERS TOWARD THE INCLUSION PROGRAM
}

By
Ragea Mohammed Alqahtani

Najran University 


\title{
The Attitudes of General Education Pre-Service Teachers Toward The Inclusion Program
}

\begin{abstract}
By
Ragea Mohammed Alqahtani ${ }^{*}$

\section{Abstract}

The purpose of this study was to examine the attitudes of general education pre-service teachers toward the inclusion program. This study has a great interest to different stakeholders, coordinators, and third parties. This study was conducted as a collective case study. It also relied on constructivism, combined with interpretivism, focused on identifying the main attitudes, perceptions, and beliefs of the general education pre-services teachers. The participants in the study were two students from a western state university; each from a different culture. There were two face-to-face interviews conducted with each participant. The interviews were audio-taped and then transcribed. The result showed that both participants' attitudes as general education pre-service teacher were positive toward the inclusion program and their perceptions and experiences with the inclusion program influenced their attitudes.
\end{abstract}

Terms Keys: Inclusion program, and General Education Pre-services Teachers. 
الغرض من هذه الدراسـة تحديد اهم الآراء والاتجاهات المواقف والتصورات والمعتقدات

الخاصـة بحالتين من طـلاب السنة الأخيرة بالجامعـة والذين يعدون في مرحلة مـا قبل الخدمـة

التعليمية نحو برنامج الدمج. وقد أجريت هذه الدراسة كدراسـة حالة جماعية. وهي تعتمد أيضـا على البنائية، و التفسيرية. كان المشاركون في الدراسة طالبين من الولايات المتحدة الأمريكية و المملكة العربية السعودي. كلا من ثقافة مختلفة. كانت المقابلات بطريقة وجها لوجه. كما انهـ تم تسجيل المقابلات صـوتيا ثم كتبتها لتوثيق جميع النقاط المهمـة في المقابلة. كانت النتائج ايجابية المعلمون تجاه برنـامج الدمج و توافق الآراء و التصور تجاه البرنامج من عدة محاور الديني و الثقافي و التعليمي. 


\section{Introduction}

Inclusion is a process which supports students with disabilities in the regular classroom (Ann, Rud, \& Michael, 2007). According to Miller and Katz (2002), inclusion is the idea of students with disabilities belonging in a regular classroom and being a respected and valued person in that classroom. Students with disabilities should feel a sense of support and commitment from the people helping them to do their best. The importance of inclusion is to give the students with disabilities the opportunity to be as valued, respected, and educated as their peers.

In the United States of America and the Kingdom of Saudi Arabia, most of the schools and universities adopted the integration process to be implemented for the students with disabilities. This implementation guaranteed students with disabilities to be included in a general education classroom and receive an equivalent education and services as the students without disabilities. The general education teachers have an extreme challenge to provide efficient services to all students (Mcleskey\& Henry, 1999). This challenge often results in various attitudes toward the program and the students. The attitudes of general education teachers affect the success of the inclusion process and definitely impacts teachers' lessons, activities, or inclusion implementations for the students with disabilities in the general classroom (Bender, Vail, \& Scott, 1995). Therefore, we focused on general education pre-service teachers who were in their senior year. 


\section{The purpose of study}

The purpose of this study was: (a) to determine what the main factors are which may affect the attitudes of the general education preservice teachers, and (b) to determine the similarities and difference between participants from different cultures. Moreover, this study aimed to identify the main issues and the appropriate intervention program to improve the attitudes of the pre-service teachers, especially if we know there is a developmental movement in Saudi Arabia schools to move from the isolated settings to inclusive settings.

\section{The Important of Study}

This study has the potential will (a) provide knowledge about general education teachers' attitudes toward the students with disabilities in classrooms, (b) maximize the effectiveness of the project from the knowledge gathered, (c) foster further research relating to the advancement of inclusion program laws in the special education field, and (d) increase the knowledge and awareness of the importance and implementation of inclusion programs.

We explored the attitudes of general education teachers toward the students with disabilities through three questions:

1- What are the perceptions of general education pre-service teachers toward students with disabilities?

2- What are the general emotional responses of education pre-service teachers when working with students with disabilities?

3- What experiences do the participants bring to teaching students with disabilities? 


\section{Literature Review}

In the literature review, there were two main points: (a) the attitudes of pre-service teachers of general education toward the inclusion program and (b) the factors which affect the attitudes of preservice teachers of general education toward the inclusion program such as the teachers' perception, emotional, and experiences. These points are extremely important because they provide the background information needed to understand the phenomenon of general education pre-service teachers' attitudes toward students with disabilities. The literature reviewed also shed light on the roles of environment, knowledge, background, experiences, culture, beliefs, and other factors.

\section{The Attitudes of General Education Pre-service}

\section{Teachers Toward the Inclusion Program}

According to El Ashry (2009), many studies have determined that the majority of the attitudes of general education pre-service teachers believe the inclusion program is crucial in the schools. The researchers also believed the inclusion program was a useful and beneficial program for the students with disabilities in the general classroom. Many general education pre-service teachers have concerns to teach the students who have behavioral disorders, significant needs, multiple disabilities, and intellectual disabilities. However, these same teachers feel comfortable teaching the students who have mild disabilities, such as learning disabilities, deaf students, or blind students (Avramidis, Bayliss, \& Burden, (2000; Cook, 2002). 


\section{The Effective Factors on the Attitudes of General}

\section{Education Pre-Service Teachers Toward}

\section{Inclusion Program ( Perception, General Emotional, and}

\section{Experience)}

Through many previous studies on the attitudes of general education pre-service teachers toward the inclusion program, four main factors had an effectiveness on the attitudes either positive or negative. The factors were: (a) the experiences of general education pre-service teachers when working with students with disabilities, (b) the nature and severity of the disability, (c) the preparation for teaching, and (d) the beliefs of the general education pre-service teachers.

1- The experiences of general education pre-service teachers when working with students with disabilities. Brownlee and Carrington (2000) indicated that the perceptions of pre-service teachers were positively affected by their interaction with students with disabilities in the general classroom. According to Hastings, Hewes, Lock, and Witting (1996), experience has an extreme influence on the perception and teaching skills of pre-service teachers. Generally, pre-service teachers with a greater level of experience with children with disabilities were more positive than those with little or no experience.

2- The nature and severity of the disability. Many general education pre-service teachers have concerns for the students who have behavioral disorders, significant needs, multiple disabilities, intellectual disabilities, and feel comfortable teaching the students who have mild disabilities, such as learning disabilities, deaf students, or blind students (Avramidis et al., 2000; Cook, 2002). 
3- The preparation for teaching the program. According to Lombard, Miller, and Hazelkorn (1998), who conducted a study in 45 state in the United States to explore the attitudes of teachers regarding the inclusion of students with disabilities, teachers who feel that they do not meet the students' needs have not had any special in-service training regarding inclusive practices. Although many of these pre-service and in-service teachers believe that general education classrooms are the best setting for students with disabilities, they have not had any special program to prepare them to teach students with special needs in settings (Sprague \& Pennell, 2000; Vaughn, 1999).

4- The beliefs of the general education pre-service teachers. According to Pajares (1992), the general education pre-service teachers' attitudes were reflected in their beliefs. Researchers have asserted that a strong relationship exist between teachers' beliefs and their interaction, understanding, knowledge, and conception of the world. Pajares, (1992) and Pomeroy (1993) found an obvious relationship between the teachers' beliefs, attitudes, and their teaching practices with students with disabilities.

\section{Methodology}

This qualitative research was conducted as a collective case study where "the one issue or concern is again selected, but the inquirer selects multiple case studies to illustrate the issue" (Creswell, 2007). Social constructivism was the epistemological framework of this paper that 
reflected the teachers' knowledge, perceptions, and interaction between them and their world (Crotty, 2003). The goal of social constructivism as a framework for this study was to explore the participants' views, attitudes, and experience as much as possible. Therefore, the questions for the interviews were broad and general in order for the participants to have an appropriate opportunity to construct the meaning of the interaction with other persons; also to find specific information to understand the historical and the culture settings of the participants (Creswell, 2007).

\section{Theoretical Perspective}

In this qualitative study, I relied on constructivism, combined with interpretivism, focusing on identifying the main attitudes, perceptions, and beliefs of the general education pre-services teachers. In this worldview, individuals sought understanding of the world in which they live and work, and they developed subjective meanings of the experiences (Merriam, 2009). The goal of the study, then, relied as much as possible on the participants' views of the situation. In other words, the attitudes, perceptions, and beliefs are not simply imprinted on individuals but are formed through interaction with others and through historical and cultural norms that operate in individuals lives (Creswell, 2007).

\section{Participants}

The participants were two adults one is 22 years old and the other one is 23 years old The participants consisted of two students from a western U.S. state university. The first participant was an American 
undergraduate student, his name is Ann. Ann's major is history, and he graduated on May 2012. The other participant was from Saudi Arabia, his name is Mish. Mish's major is educational technology, and he graduated May 2012. The participants were contacted via the official email system of the university (www.unco.edu) and the Saudi Students Club at the university (www.saudiunc.org). They received an Informed Consent Form that included an explanation of this study's proposal, procedures, risks, and participants rights (see Appendix A). The participants were informed about an initial interview which consisted of 10 questions (see Appendix B) about their attitudes toward the inclusion program and the follow-up interview if I needed to clarify any part of the participants' views and attitudes.

\section{Setting}

This study was implemented at a western state university. The initial interview was conducted at the university and took about 25-35 minutes with each participant. Each participant worked or taught in a general classroom that included students with disabilities. This study was a required assignment at any school in the northern city of a western state. Also, the participants were provided with important documents which explained the most important points of the inclusion program. Finally, the follow-up interview was conducted with the participants in an environment of their choice.

\section{Data Collection}

All interviews were conducted in the face-to-face format. The first interview was conducted at the university. The second interview 
occurred in a favorite place of the participants (I did the second interview with the Saudi participant at his home and with the American participant at University of Northern Colorado library). Semi-structured interview protocol was used. This is where we asked open-ended questions. Each interview was audio taped and then saved in a special computer file. After that, it was transcribed into a Microsoft Word document.

\section{Analysis}

Four steps were utilized to analyze the collected data. These steps were: (a) interviews were recorded and notes taken which included many points about the most important procedures, and issues while conducting the interviews; (b) listening and re- listening to each participant's answers carefully; (c) transcribing the tape recordings of the participants' answers; (d) identifying or specifying the most important answers which were related to the purpose of this study and then organized or divided them into three categories based on the main three questions of the study. Finally, I identified the themes related to each main question of this study.

\section{Trustworthiness}

According to Lincoln and Guba (1985) there are four aspects of trustworthiness which should be considered and implemented to reach a high level of validity and reliability. These issues are credibility, transferability, dependability, and confirmability. Credibility is an evaluation process for the interpretation of the collected data which reflects the real participants' views. It assisted the researcher in 
clarifying if the findings were congruent with reality of the collected data or not. Transferability is the degree to which the researcher can implement the findings beyond the bounds of study. Merriam (2009) stated that, "it is concerned with the extent to which the findings of one study can be applied to other situations". Dependability is an process of evaluating the quality of data collected, analyzing data, identifying findings, and generating the results of research. Confirmability is an evaluation process which assesses how the researcher's findings are associated to the data collected. In 2004, Andrew wrote that, "The concept of confirmability is the qualitative investigator's comparable concern to objectivity"

For credibility, there are two methods that can be implemented to ensure the accuracy of the participants' responses. The first method is the development of a comprehensive set of questions for study. The second method pertains to participant check and peer check. For the participant check, each participant reviewed her/his responses after the transcription process to ensure the accuracy of the collected data. In addition, each participant reviewed the results obtained from the interviews to ensure that their attitudes toward inclusion program were reflected. Peer check involved consultations with my advisor Dr. Murry Francie (Professor of Special Education) and Dr. Richard Veronica (Professor of English) who are both from the University of Northern Colorado, as well as three other individuals who have performed qualitative research. 
For transferability, responses were collected from all participants as a group; even if the response is just "Yes." After this process, the group was divided into three subgroups based on responses to the study questions. Data then was determined based on the main three study questions. The last step was to determine the main themes obtained from the responses of each participant.

For dependability, two interviews were conducted with each participant. These interviews were recorded via audio iphone recording and transcribed into separate Microsoft Word documents for each interview, respectively. This process was done carefully to ensure that transcription of the recordings is done as precisely as possible.

For confimability, main themes were identified from the responses collected and divided into three categories. These categories were participants' perceptions, emotional responses, and experiences. Furthermore, triangulation was informed by identifying the participants' attitudes toward the inclusion program that contributed to increasing the validity and reliability of the study.

\section{Findings}

I present the findings according to the three main questions:

RQ1: What are the perceptions of general education pre-service teachers toward students with disabilities?

RQ2: What are the general emotional responses of education preservice teachers when working with students with disabilities?

RQ3: What experiences do the participants bring to teaching students with disabilities? 
The participants in the study included one Saudi Arabian teacher, Mish, and one American teacher, Anna. The main themes emerged from the participants' responses to 13 questions.

\section{What are the perceptions of general education pre-service teachers toward students with disabilities?}

We identified six themes surrounding the first study question, including: (a) the goals of inclusion program implementation, (b) the implementation of Individual Education Program (IEP), (c) why the inclusion program is beneficial, (d) efficient training and accommodation effectiveness, (e) environment and time effectiveness, and (f) the effectiveness of social and educational communications, and differentiation in teaching.

The goals developed for inclusion program implementation: The question asked the participants what they would say to a parent while explaining the inclusion program. Though their responses, general information about how the inclusion program was particularly beneficial for students with disabilities was provided. They supported the concept of the inclusion program being implemented in the schools. This reflected that they had a supportive perception toward the inclusion program.

Mish's response was,

"Inclusion in education is providing education for a child to the maximum extent in the classroom he or she would have otherwise attended. With inclusion, services are provided to the children in their classroom. It is an important program to provide services that will help the child as an individual and not have the need to keep up with other students in the classroom." 
Ann's response was,

"It is really nicely to see students with disabilities in the general classroom; they will feel comfortable more than when they are in single or isolated room. So I believe that the inclusion program is a supportive program for students with disabilities."

The implementation of Individual Education Program (IEP). The question asked what they thought when someone said Individualized Education Program. Explain? Through their responses, they provided a valuable understanding of the importance of IEP. They had supportive perceptions toward IEP which is considered a significant procedure in implementing the inclusion program successfully. The educational aspect showed in their responses that they appeared to have a high knowledge of the importance of IEP and how it associated with the inclusion program.

Mish responded,

"IEP is mandated. It helps educators develop goals for students that are weak in certain academic areas. The IEP should describe how the student learns, how the student best demonstrates that learning and what teachers and service providers will do to help the student learn more effectively. I believe every child that requires services will definitely benefit from an IEP."

Ann answered,

"It is a benefit for the students; if it is used correctly it is going to be beneficial. When the inclusion program is used 
correctly, the children and their parents will realize its benefits. And I believe that when the team work collaboratively and they follow the instruction of IEP implementations, they will see a positive changing on the student behaviors and performance."

Why the inclusion program is beneficial. The question asked the participants about what the advantages were of the inclusion program for them as a general education pre-service teacher and for students with disabilities and to explain why they thought each one was an advantage of inclusion program. Through their responses, both of the participants had an extremely helpful perception toward the inclusion program's benefits. They thought it guaranteed the quality life for students with disabilities that would be similar to their peers who were not disabled.

Mish responded,

"In my opinion, the main advantage of the inclusion program is giving the child the opportunity to be appropriately educated in the classroom and actually giving the child a chance to be like other kids. I believe having the opportunity to achieve and interact and succeed and fail like the others can really do a lot for a child's sense of self-worth. Children that have undergone an inclusion program can actually feel that they have truly accomplished something and have learned. The biggest worry most children, especially older ones, face is how will I survive in college when I do not have all the resources I have been provided with in my school years? With inclusion, children are able to learn to adapt to classroom situations and apply what they 
learned as they move on in their academic lives. Also, the more children are included in classrooms, the less likely they are to miss out on important social events going on in class. Last but not least, I as a regular education teacher am able to know more about the performance of my students in and out of the classroom."

Ann responded,

"The benefit is to diversify help teachers to change their plan weakly because the students with disabilities, they need special help. So the teacher have to think about that they will provide the same lecture but through a different way. The benefit for the student is to help them to gain the information and ideas from a different way and that saves their educational rights."

The effectiveness of efficient training and accommodation. The question asked the participants about what the disadvantages were of the inclusion program for them and students with disabilities? Through their responses, they identified two main disadvantages which were (a) the teachers show inappropriate behavior toward students with disabilities and (b) sometimes they fail in implementing the inclusion program successfully. The participants attributed these disadvantages to two reasons: (a) the general education teachers do not have qualified training and experience, (b) discriminating actions toward the students with disabilities. 
Mish responded,

"The biggest disadvantage of the inclusion program is that usually classroom teachers are not adequately trained to deal with students with disabilities or, at times, the classroom itself does not have the necessary accommodation or tools to accommodate the students need to help him/her succeed. Also let's face the facts, students these days are brutal. They will jump at any chance they could get to make fun of students with disabilities. Including students with an apparent disability in a classroom would make them candidates for bullying and name calling."

Ann responded,

"The disadvantage happens when the teacher does have a good experience in implementing the inclusion program, also when the general teacher does not do correct such he/she can't deal with the students with disabilities or he could not support that student to be involved so that will effect on the student with disabilities that they feel they are not contacted in the class, and they become anxious."

The effectiveness of the environment and the time. The question asked the participants about how they evaluated the effectiveness of the inclusion program on the performance of students with disabilities? Through their responses, they believed that the inclusion program had a positive effect on the academic and exceptional skills and performance of students with disabilities. Also, they thought that environment and time had a strong effect on the implementation of the inclusion program. 
Therefore, they appeared to have positive thoughts about the inclusion programs' effectiveness through their perceptions.

Mish responded,

"I am in no position to judge the effectiveness of the inclusion program for I have seen it succeed with some students and was a big failure and waste of time with other students. Many parents as well as their child were extremely satisfied and happy with the accomplishments made with the inclusion program; others were extremely dissatisfied and did not want their child to be part of the inclusion program. Each child is different, and our role as educators is to place students in the environment that will best meet their needs. Not all students will benefit from inclusion, however, many will. Nonetheless, the students that benefited from inclusion program have improved significantly academically and socially. I have seen some shy, withdrawn, and at times, troubled kids blossom into active, social, and enthusiastic kids when they went through the inclusion program. It definitely has its strengths, but as I mentioned before, it may not be suitable for all students with disabilities."

Ann responded,

"Actually, I have not read or seen. It is a new technique... which becomes implemented in the classroom. I think there is effectiveness. I think it is positive technique, to there is a positive effect on the students, it is really supportive one. And I think there is a matter or an issue that when I work with students with disabilities a long time. Maybe that will effect on the other 
students with disabilities like jealously, but I believe most of the students without disabilities they understand why I'm doing that. As general there is no any negative effect."

The effectiveness of social and educational communication, and differentiation in teaching: The question asked the participants if they thought that students with and without special needs had benefits from inclusion. Why? Through their responses, they believed that the inclusion program was useful for the students whether with or without disabilities, socially and educationally. However, they thought there were some other factors such collaboration among IEP's team effect preventing them from reaching the desired goals or results at a satisfactory level.

Mish answered,

"Socially speaking, I am in favor of inclusion. I think it is important for children to be socially integrated with all sorts of people who are different from them in order to learn how to behave appropriately in the face of those differences. Educationally speaking, however, I sometimes find it is useful."

Ann answered,

I think that all students, with or without special needs, benefit from inclusion because of the teacher having to differentiate their teaching delivery. This will allow all students to gain a better understanding of what the teacher is trying to explain to them. This adds diversity to the classroom which decreases the possibility of the class becoming stagnant." 


\section{What are the general emotional responses of education pre-} service teachers when working with students with disabilities?

I identified two themes surrounding the first research question, including: (a) the effects of religion, culture, and personal attitudes and (b) the effectiveness of students with disabilities in the regular classroom.

The effects of religion, culture, and personal attitudes. The question asked the participants to explain what they thought about the inclusion program through four aspects, such as education, religion, culture, and personal emotional. Through their responses, they supported the inclusion program and believed it was necessary. the culture and religion, the Saudi Arabian participant believed there was no effect from the cultural or religion aspects whether positive or negative on her attitudes. However, she believed her religion supported the equality among people. She also indicated there was a kind of racism from some parents of the student without disabilities toward students with disabilities. Therefore, they forced the teacher to isolate students with disabilities into separated rooms. The American participant believed there was a negative effect when the parents do not know the inclusion program or they have an unclear perception toward the inclusion program. He believed his religion supported students with needs to have their educational and life equality as their peers.

Mish responded,

"I am for and also against inclusion on certain levels. I believe that no one has to choose one or the other. You can have a student be in a regular class for some classes and in another for 
others if it is appropriate. It is not all or nothing. The main goal is to place students appropriately and to provide them with the best services that would meet their needs. So, my opinion on inclusion is, I am for it if it is appropriate for the child and meets the needs of the child. I am against it if it doesn't. I know the child has a right to Least Restricted Environment. Also as a school we need to be mindful of the regular education students in that classroom. It should not take away from their time. Make sure both populations are having their academic needs met. Bottom line, put the students in the most appropriate, leastrestricted environment needed to meet his needs. Provide the modifications (e.g., aide) in order to assist and not distract other students. Unless parents request they don't want their child to be in the inclusion program for personal reasons, I honestly don't see how religion and culture could influence decision about inclusion placement and implementation."

Ann responded,

"It is great it needs to be in school because that is supportive our children with disabilities to feel equal and comfortable. My religion supports equal among people. Culture aspect, I believe if the people are not more educated they do not know it, but when they know it and know what the benefits form it they will support. There, I can say there is no clear attitude from the culture toward the inclusion program. Personal aspect, I am supportive that to see the inclusion program to be implemented into the schools whether private or public." 
The effectiveness of students with disabilities in the regular classroom. The question asked the participants if they thought students with Special needs may have a negative effect on the classroom environment. Why? Through their responses, they thought there was a negative effect. They indicated that it was not caused from the inclusion program. They felt the negative impact could be from the implementation of the inclusion program being unprepared and unorganized.

Mish responded,

"Yes and no. Sometimes I spend a great amount of time preparing and modifying lessons for the special students, which takes a way time for the other students and frankly, this may hinder their progress. I know it is my responsibility to make sure that all students are receiving proper education, but let's be realistic here, a teacher has a million things to do already."

Ann responded,

"I think that this depends on what type of regular students that is in the classroom. If the students have been exposed to special needs students in the classroom then this is different because they are used to the teacher having to accommodate both the general students and the special needs students. If the students are not used to having students with special needs in the general education classroom then this throws the students off from their habits and the way that they learn." 


\section{What experiences do the participants bring to teaching students with disabilities?}

I identified seven themes surrounding the first research question, including: (a) the inclusion program becomes one of the important educational programs, (b) motivation and understanding the students' needs, (c) why the informal plan is important for inclusion program, (d) the effectiveness of the academic skills (writing, reading, etc, (e) why is the guideline work sheet is important for inclusion program, and (f) the equality chance to work for general education teachers in understanding and implementing inclusion program.

the inclusion program becomes an important educational program. The question asked the participants about where/how they saw the inclusion program among the educational programs in schools. Through their responses, they believed the inclusion program was one of the most important educational programs. They also reflected that they had successful experiences with inclusion program and appeared to have a positive personal stance toward it.

Mish responded,

"Any program implemented in a school is striving to provide services to a child that best meets his needs to help him/her succeed. I view the inclusion program as another program that can be implemented that could be a valuable resource for students and educators."

Ann responded,

"I see the inclusion program is the most important program because I believe that it is considered to be implemented is a 
supportive with another part. For example, if I have a special program of writing for the students without disabilities, but I have also students with disabilities so I will need to implement the inclusion program because I believe that it is one of the important top programs in schools."

Motivation and understand the students' needs. The question asked the participants about describing a time when you had been successful with students with disabilities. Through the participants responses, both of them had a successful experience when they worked with students with disabilities. However, they believed there were some other factors that had an effect on their work experiences, which sometimes prevented the teachers from implementing the inclusion program successfully, such as: IEP's implementation, the collaboration among the IEP's team, parents' role, and so on.

Mish responded,

"There were many times when I was successful with a student that had a disability. I had a student that was mentally challenged placed in my classroom. He had an IEP. He was functioning way below grade and age level and had a paraprofessional in the class with him at all times. The support he had from his parents was phenomenal. He was an enthusiastic and very motivated student. He struggled a lot, and at times, he was made fun of by other students. However, that didn't stop him. The progress he made from when he was first entered my classroom to the last day of school was outstanding. His reading improved tremendously (however, he was still below grade level), 
his math skills also slightly improved, but his writing skills were still relatively weak. Nonetheless, to see an improvement in one academic area is amazing. That is a story of success!!"

Ann responded,

"Actually, I have worked with students with disabilities, but I want to talk about a student I worked with him last semester. I was with working with him two classes daily. I was sitting with him and work with him individually to help him to understand the topics of history. His problem was his writing, and he was struggling to take a note. I could help him to take a note how he wrote about the ideas about each paragraph. I was working with him successful and I did not have any difficulties in working with him."

Why does the informal plan is significant for inclusion program? The question asked the participants about how they taught in a class that included students with disabilities. Through their responses, they provided extensive details about their successful experiences in working with students with disabilities, except sometimes the teacher faced some difficulties with students with disabilities, especially when the students had academic needs, deficit in accommodation, materials, and other supportive tools in the classroom.

Mish responded,

"Not all would have an IEP; however, an informal plan would be developed with the special education teacher and the counselor. If a child had severe disabilities, I'd always request a paraprofessional to work with him or her." 
Effectiveness of the academic skills (writing, reading, etc).

Mish answered,

"Most of the students with disabilities were below grade level academically, especially in the area of reading and writing, therefore, they received many accommodations and assignments that met their needs. That included reading books at the particular child's reading level. Any assignments or expectations would be at the grade level he is currently at academically."

Why does the guideline work sheet is important for inclusion program?

Ann answered,

"I was giving guideline for the students; I was thinking to help them to follow my class procedures and ideas. So when they have the same guideline or sheet, they feel that we are a part of the class because they have the same material like the students without disabilities. But I provide an extra help or explanation for them. I mean I explain that work sheet to the whole class, but I consider that I have to provide special help for the students with disabilities if they need that and through indirect help."

The equality implementing inclusion program of general education teachers. The question asked the participants if they thought that general education teachers had sufficient expertise/training for inclusion. Explain. Through their responses, they believed that they did not have sufficient experience for implementing the inclusion program successfully. However, they thought that they were adequate to help the students with disabilities in the general classroom. 
Mish responded,

"And I know I am not adequately trained to help these students, and frankly with the amount of work I already have with regular students, it's hard to plan for special kids

Ann responded,

"To give my best answer I would say no because the STEP program only requires the teacher candidates to take 1 class in the EDSE field so I think that the teacher candidates coming from UNC do not have sufficient training in teacher students with special needs.'

\section{Eonclusion}

Mish and Ann's attitudes during this study provided important background to the attitudes of general education pre-service teachers toward the inclusion program. Through identifying and analyzing the themes of each research question, I reached significant results of this study.

Through analyzing the themes of the first research question (What are the perceptions of general education pre-service teachers toward students with disabilities?), Mish and Ann had an extremely excellent perception about the inclusion program and showed they had an extremely high awareness of its importance and benefits. Additionally, they realized there were other programs such as Individual Education program (IEP), which contributed to implementing the inclusion program successfully. The results of this study came to support the results of El Ashry's (2009) indicated the general education pre-service teachers believed the inclusion program was crucial in the schools. 
Through analyzing the second research question (What are the general emotional responses of education pre-service teachers when working with students with disabilities?), there was no significant effect on attitudes of Mish and Ann toward the inclusion program from culture or religion aspects. Therefore, there was no relationship between the general education pre-service teachers' attitudes and their beliefs. The results are against the results of the Pajares's research when he indicated that the general education pre-services teachers interacted with the students with disabilities through their beliefs (Pajares et al., 1992).

Through analyzing the themes of third research question (What experiences do the participants bring to teaching students with disabilities?), the participants had extremely successful experiences in implementing the inclusion program and that effect had a positive on their attitudes toward the inclusion program. Therefore, there was a significant relationship between the general education pre-service teachers' attitudes and their experiences with inclusion program. The results resorted match to the results of Hastings's research, when he indicated that experience had an extremely significant influence on the general education pre-service teachers' attitudes toward the inclusion program (Hastings et al., 1996).

\section{Implications for the Field}

In this study, the participants provided important responses of the general education pre-service teachers' perceptions toward the inclusion program. The participants' understanding contributed to increasing the awareness of the general education teachers' role for providing equal education to the students with disabilities through the inclusion program. Additionally, this study, with its questions, ideas, literature reviews, 
results, all procedures, and applications, provided a good perspective of how the general education teachers' perceptions and experiences had an extremely significant influence on the inclusion program's implementation. I believe this study supported the implementation of the inclusion program into schools and focused on increasing the general education teachers' skills and abilities to implement the inclusion program successfully.

\section{Future Research}

I would encourage further study related to the personal emotional aspect and how that influences the general education pre-service teachers' attitudes toward the inclusion program. I would develop two more interviews which include at least 10 comprehensive questions about culture and belief effects. Also, I would recommend that observation process could be conducted in their work environments and record their work by using a particular form which is always used with practicum courses. In future research, I would focus on developing a particular training program which would increase the general education pre-service teachers' perceptions and Skills of the inclusion program.

In conclusion, Mish and Ann's attitudes as general education preservice teacher were positive toward the inclusion program and their perceptions and experiences with the inclusion program influenced their attitudes. The general education teachers' role is extremely important for implementing the inclusion program in the general classroom, and to ensure that students with disabilities receive the same educational rights as their peers without disabilities. The general education pre-service teachers have to have an excellent perception of the inclusion program and do two or three practices in school about how they work or tech students with disabilities with their peers in general classroom. 


\section{References}

Ann, T., Rud, T., \& Michael, L. (2007). Exceptional lives special education in today's school. New Jersey: Merril Prentice Hall.

Avramidis, E., Bayliss, P., \& Burden, R. (2000): A survey of mainstream teachers' attitudes towards the inclusion of children with special educational needs in the ordinary school in one local educational authority. Educational Psychology, 20, 191-211.

Bender, W. N., Vail, C. O., \& Scott, K. (1995). Teachers' attitudes toward increased mainstreaming: Implementing effective instruction for students with learning disabilities. Journal of Learning Disabilities, 28, 87-94.

Brownlee, J., \& Carrington, S. (2000). Opportunities for authentic experience and reflection: A teaching program designed to change attitudes towards disability for preservice teachers. Support for Learning, 15, 99-105.

Cook, B. G. (2002). Inclusive attitudes, strengths, and weaknesses of pre-service general educators enrolled in a curriculum infusion teacher preparation program. Teacher Education and Special Education, 25, 262-277.

Creswell, J. W. (2007). Qualitative inquiry \& research design: Choosing among five approaches. Thousand Oaks, CA: Sage.

Crotty, M. (2003). The foundations of social research: Meaning and perspective in the research process. London, England: Sage.

El Ashry, F, R. (2009). Information retrieval techniques: General education pre-service teachers' attitudes toward inclusion in Egypt (Doctoral dissertation, University of Florida). Retrieved from http://etd.fcla.edu/UF/UFE0024244/elashry_f.pdf 
Hastings, P., Hewes, A., Lock, S., \& Witting, A. (1996). Do special educational needs courses have any impact on student teachers' perceptions of children with severe learning difficulties? British Journal of Special Education, 23, 139-144.

Lombard, R. C., Miller, R. J., \& Hazelkorn M. N. (1998). School-towork and technical preparation: Teacher attitudes and practices regarding the inclusion of students with disabilities. Career Development for Exceptional Individuals, 21, 161-172.

Merriam, S. B. (2009). Qualitative research and case study applications in education. San Francisco: Jossey-Bass.

Miller, F. A., \& Katz, J. H. (2002). The inclusion breakthrough: Unleashing the real power of diversity. San Francisco: BerrettKoehler Publishers

McLeskey, J., \& Henry, D. (1999). Inclusion: What progress is being made across states? Teaching Exceptional Children, 31(5), 5662.

Pajares, F. (1992). Teachers' beliefs and educational research: Cleaning up a messy construct. Review of Educational Research, 62, 307-332.

Pomeroy, D. (1993). Implications of teachers' beliefs about the nature of science: Comparison of the beliefs of scientists, secondary science teachers, and elementary teachers. Science Education, 77, 261-278.

Sprague, M. M., \& Pennell, D. P. (2000). The power of partners: Preparing preservice teachers for education. Clearing House, 73, 168-170.

Vaughn, S. (1999). Kindergarten teachers' perceptions of instructing students with disabilities, Remedial and Special Education, 20, 184-192. 


\section{APPENDIX A \\ INFORMED CONSENT FOR PARTICIPATION IN RESEAREH}

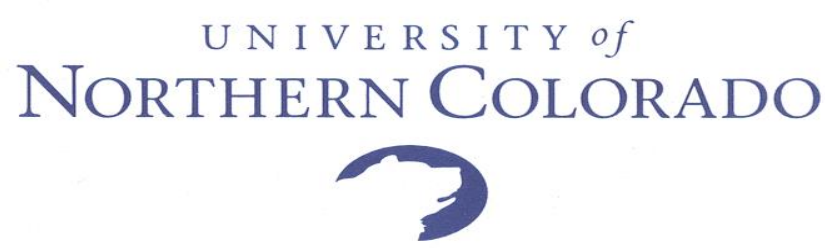

\section{Informed Consent for Participation in Research}

University of Northern Colorado

Project Title: The Attitudes of General Education Pre-Services Teachers toward the Students with Disabilities.

Researcher: Ragea M Alqahtani, Department of Special Education

Phone Number: (970) 313-7052

Since I became a special education teacher, I have been interested in preserving the rights of students with disabilities in the general classroom. Therefore, I am now conducting a study in which I am interested in understanding teachers' perceptions concerning students with disabilities. I am interested in knowing what you think about students with disabilities, the inclusion program in our schools, and what you believe assists your work with students with disabilities.

If you decide to help me pursue this topic, you will be agreeing to two main interviews. The first interview will be in March of 2011, and the second one will be in April of 2011. Each of the interviews will take approximately 45 minutes and will include 10 questions. You will have the opportunity to read the questions ahead of time and choose not to answer any question that you think you do not feel comfortable with. The interviews will take place in an appropriate area at UNC. 
I foresee no risks to participating in this study. However, you might feel fatigued due to the length of the interviews. If this occurs, I will end the interview for that session. You also may withdraw from the study for any reason without any repercussions. By participating in this study, it will in no way affect your grade in the EDSE 325 course or the Saudi Club membership. This process is separate of these activities.

The important benefits of participating are: (a) furthering the educational rights of the disabled students in order to keep track of developments and emerging needs, (b) gaining awareness and developing your knowledge and attitudes toward the students with disabilities, and (c) receiving follow-up contact to ensure the inclusion programs is understandable and preferable to you.

Please feel free to contact me if you have any questions. My cell phone is 970-313-7052 and my email is alqa3692@bears.unco.edu. Thank you for your consideration and collaboration in this research.

Participation is voluntary. You may decide to withdraw your participation in the study at any time. Your decision will be respected and will not result in loss of benefits. Having read the above and having had an opportunity to ask any questions, please sign below if you would like to participate in this research. A copy of this form will be given to you to retain for future reference. If you have any concerns about your selection or treatment as a participant, please contact the Sponsored Programs and Academic Research Center, Kepner Hall, University of Northern Colorado Greeley, CO 80639; 970-351-1907.

Preservice Teacher's Signature

Researcher's Signature

\section{Date}

Date 


\section{APPENDIX B}

\section{THE FIRST INTERVIEW QUESTIONS}

1- If you were explaining the inclusion program to a parent, what would you say?

2- If I say Individualized Education Program, what do you think? Explain?

3- Of the many programs in school, where/how do you see the inclusion program fitting among them?

4- Describe a time when you have been successful with students with disabilities.

5- Describe a time when you have been less successful with students with disabilities.

6- Describe how you taught in a class that includes students with disabilities? Please provide details.

7- What are the advantages of the inclusion program for you as a general education teacher and for students with disabilities? Explain why you think each one is advantage of inclusion program?

8- What are the disadvantages of the inclusion program for you and for students with disabilities?

9- How you evaluate the effectiveness of inclusion program on the performance of students with disabilities?

10- Finally, explain what do believe about the inclusion program through four aspects such as education aspects, religion aspects, culture aspect, and personal feeling aspects? 


\section{APPENDIX C}

\section{THE FOLIOW-UP INTERVIEW QUESTIONS}

1) Do you think that students, with and without special needs, benefit from inclusion? Why?

2) Do you think that students with special needs may have a negative effect on the classroom environment? Why?

3) Do you think that general education teachers have sufficient expertise/training for inclusion? Explain. 